\title{
PRIMENA STATISTIČKE METODE U ANALIZI ISKORISTIVOSTI DRVNOG OTPADA IZ PROIZVODNJE ŠPERPLOČA U FABRICI WIZARD- VRŠAC
}

\author{
Dr Jelena Milanović \\ Visoka poslovna škola strukovnih studija „Prof. dr Radomir Bojkovićc“ Kruševac \\ e-mail: milanovic0602@gmail.com
}

\section{Sažetak}

Nakon ratifikovanja Kjoto protokola $u$ parlamentu Srbije krajem 2007. godine, trebalo je da Vlada postavi institucionalni okvir za realizaciju takozvanih CDM projekata, to jest projekata čistog razvoja. Projekti zamene fosilnih goriva drvnim otpadom ili peletima za proizvodnju energije, mogli bi predstavljati dodatni prihod prodajom količina smanjene emisije $\mathrm{CO}_{2}$.

Industrija bazirana na šumskom drvetu predstavlja značajnu privrednu granu $u$ Srbiji, sa relativno visokim udelom $u$ bruto nacionalnom proizvodu (1,24\%) $i$ obimu industrijske proizvodnje (3,63\%) [1].

Drvo spada u obnovljiv izvor energije. $U$ svim fazama proizvodnje šperploče (skidanja kore sirovog drveta, rezanje, struganje, mehanička obrada brušenjem) generiše se drvni otpad koji može biti izvor energije, neophodan za izvodjenje dela tehnoloških operacija. U radu će biti predstavljeni udeli pojedinih otpadnih sirovina, kao i energetska ušteda korišćenjem sekundarne sirovine.

\section{Abstract}

Kyoto Protocol was ratified by the Serbian Parliament at the end of 2007. The Government of Serbia should be establishing an institutional framework for the implementation of the so-called CDM (clean development mechanism) projects, i.e. projects of clean development. Projects that replace fossil fuels with wood waste and wood pellets for energy could be an additional income by selling quantities of $\mathrm{CO}_{2}$ emissions.

Industries based on forest tree represent a significant economic sector in Serbia, with a relatively high proportion of the gross domestic product (1.24\%) and industrial production (3.63\%) [1].

Wood is one of the renewable energy sources. Wood waste, which can be a source of the energy necessary for the execution of some of the technological operations, can be generated in all stages of the production of plywood (peeling raw wood, cutting, scraping, mechanical processing by grinding). The paper will present us with the shares of certain waste materials, as well as energy savings by using recyclable materials.

Ključne reči: metode, drvni otpad, energetska ušteda

Keywords: methodes, wood waste, energy saving 


\section{Uvod}

U poslednjih nekoliko decenija pojavila se značajna zabrinutost zbog uticaja otpada na životnu sredinu. Upravljanje otpadom ima širok spektar mogućih uticaja na životnu sredinu, budući da prirodni procesi učestvuju u raznošenju zagađujućih materija i otrovnih supstanci u svim medijima životne sredine. Priroda i dimenzija ovih uticaja zavise od količine i sastava otpada, kao i metode usvojene za njihovo tretiranje. Nepravilno upravljanje otpadom je izazvalo brojne slučajeve zagađenja zemljišta i podzemnih voda, ugrožavanje prirodnog funkcionisanja ekosistema i zdravlja izloženog stanovništva [2].

Sve ljudske aktivnosti su potencijalni izvori otpada: one tokom ekstrakcije, proizvodnje, distribucije $i$ finalne potrošnje robe $i$ usluga, kao i tokom sakupljanja i tretmana (npr. sortiranje ostataka u opremi za reciklažu i peći za spaljivanje). Građevinarstvo, eksploatacija rude i kamena, prestavljaju proizvodne aktivnosti koje su prema količini glavni izvori otpada u Evropskoj uniji. Trećina ukupnog otpada u EU-27 (970 miliona tona) potiče iz građevinskog sektora. Četvrtina (741 miliona tona) je otpad iz rudnika i kamenoloma. Proizvodne aktivnosti generisale su 364 miliona tona otpada. 215 miliona tona otpada vodi poreklo iz domaćinstava, ili $7 \%$ od ukupnog otpada generisanog u 2006. godini.

Relativno učešće različitih izvora otpada varira među pojedinim zemljama, u skladu sa sopstvenom ekonomskom strukturom. Industrija, koja uključuje i eksploataciju rude i kamena, proizvodnju električne energije, gasa i vode, kao i proizvodne aktivnosti i izgradnju, glavni je generator otpada u svim zemljama EU, osim Letonije, gde su domaćinstva osnovni generatori otpada [2].

Drveni otpad sastoji se od drvnih ostataka industrijskog porekla. To može biti kora, drvni industrijski čipovi, industrijsko drvo niskog kvaliteta, piljevina, strugotina, itd. Proizvodi iz šumarstva (ostaci od seče drveta, oblo drvo za energiju, drvo za ogrev) nisu uključeni i tretiraju se kao zasebne kategorije goriva, (piljevina ili ogrevno drvo) prema nacionalnoj energetskoj statistici. Otpad koji potiče od polovnog nameštaja i drveni otpad koji sadrži zagađivače poput lepka, farbe ili konzervansa nije uključen u drveni otpad pošto se ove frakcije moraju klasifikovati kao industrijski otpad i tretiraju se $u$ objektima za spaljivanje otpada [3].

U 2009-oj godini obnovljivi izvori energije obezbedili su $9 \%$ od ukupne bruto domaće energetske potrošnje u EU-27. Drvo i drveni otpad je vodeći obnovljivi izvor energije. Skoro polovina potrošnje obnovljivih izvora energije u EU-27 potiče od drveta i drvnih otpadaka. Ova informacija preuzeta je iz poblikacije „Forestry in the EU and the world" (Šumarstvo u EU i svetu), izdate od strane Eurostata, statističke kancelarije Evropske unije, povodom Međunarodne godine šuma, 2011. Međunarodna godina šuma bila je prilika da se podigne svest javnosti o značajnim ekološkim i ekonomskim doprinosima šuma.

Poznato je da Srbija ima značajan potencijal biomase koji se procenjuje na 2,7 miliona tona ekvivalentne nafte (ten). Oko 40 odsto potencijala obnovljivih izvora energije (OIE) potiče od korišćenja biomase, od čega 1,0 Mten je potencijal drvne biomase (seča drveća i ostaci biomase drveta tokom primarnog $\mathrm{i} / \mathrm{ili}$ industrijskog tretmana), a preko 1,4 Mten je poljoprivredna biomasa (ostaci poljoprivrednih kultura uključujući i tečni stajnjak) [4].

Statistički podaci o doprinosu drveta/drvnog otpada, dostupni od 1990. godine, pokazuju da korišćenje drvne biomase za proizvodnju toplotne energije raste brže od direktne upotrebe drveta $u$ domaćinstvima i industriji [5]. Preduzeća u Srbiji proizvela su oko $13.000 \mathrm{~m}^{3}$ šperploče u 2005. godini [6]. Međutim, ova proizvodnja je još uvek manja nego 1990. 
godine. Očekuje se da u narednih nekoliko godina proizvodnja šperploče dostigne visok nivo proizvodnje iz 1990. godine. Dva osnovna uslova za to su: postojanje tržišta i raspoloživa sirovina. Šperploče od topole se proizvode u Vojvodini, a od bukve u centralnom delu Srbije.

\section{Materijal i metode}

$\mathrm{Za}$ analizu iskoristivosti drvnog otpada $\mathrm{u}$ proizvodnji šperploče upotrebljeni su podaci iz proizvodnje, odnosno generisanja čvrstog otpada u pojedinim fazama prerade drvne građe u drvo za izradu šperploče u fabrici šperploče Wizard-Vršac.

\section{Analiza rezultata}

Prema podacima o fizičkom obimu proizvodnje u 2010-oj godini preradjeno je $145.000 \mathrm{t}$ neobradjenih trupaca $\mathrm{u}$ finalni proizvod. Iz datog obima proizvodnje nastalo je 45.000t otpadnog drvnog materijala ili $31 \%$ u odnosu na početni sirovi materjal. Otpadni materijal se prema fazi prerade u kojoj nastaje može podeliti na nekoliko vrsta otpada. Grafički je to predstavljeno na slici 1.

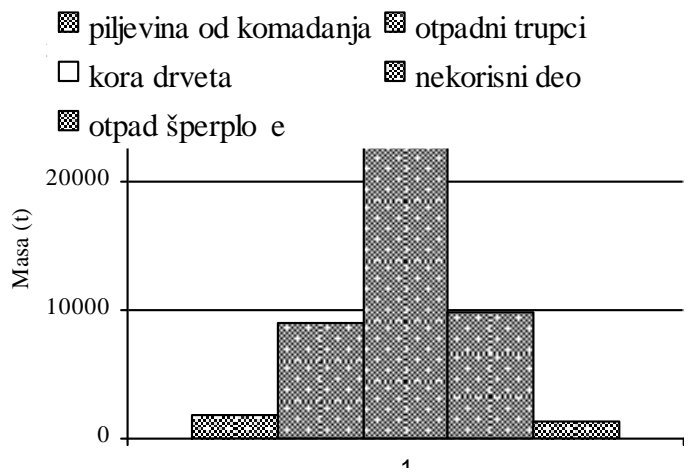

Slika 1. Struktura otpadnog drvnog materijala prema fazi proizvodnje u kojoj nastaje

Procentualno učešće pojedinih vrsta otpadnog drvnog materijala dato je u tabeli broj 1 , gde se može videti da kora drveta čini najveći deo drvnog otpada.
Tabela 1. Učešće otpadnog drvnog materijala prema mestu nastanka (\%)

\begin{tabular}{|c|c|}
\hline Vrsta otpada & $\begin{array}{c}\text { Učešće } \\
(\%)\end{array}$ \\
\hline Piljevina & 4 \\
\hline Otpadni trupci & 20 \\
\hline Kora drveta & 51 \\
\hline Nekorisni deo drveta & 22 \\
\hline Otpad šperploče & 3 \\
\hline
\end{tabular}

$\mathrm{Na}$ osnovu podataka o zapremini, odnosno masi stvorenog otpada po kvartalima, kao i podatka da je toplotna moć otpadnog drveta topole, koja se koristi za preradu, 18-22 $\mathrm{MJ} / \mathrm{kg}$ izračunata je raspoloživa kalorijska vrednost otpadnog drvnog materijala u toku jedne godine. $\mathrm{Za}$ izračunavanje kalorijske vrednosti uzeta je toplotna moć od 17,26 $\mathrm{MJ} / \mathrm{kg}$ (tabela 2).

Tabela 2. Ostvarena kalorijska vrednost otpadnog drvnog materijala po kvartalima (GJ)

\begin{tabular}{|c|c|c|c|}
\hline Kvartal & $\begin{array}{c}\text { Zapremina } \\
\left(\mathrm{m}^{3}\right)\end{array}$ & $\begin{array}{c}\text { Masa } \\
(\mathrm{t})\end{array}$ & $\begin{array}{c}\text { Kalorijska } \\
\text { vrednost } \\
(\mathrm{GJ})\end{array}$ \\
\hline I & 26000 & 11700 & 201942 \\
\hline II & 26600 & 11970 & 206602,2 \\
\hline III & 27400 & 12330 & 212815,8 \\
\hline IV & 20000 & 9000 & 158400 \\
\hline & 100000 & 45000 & 776700 \\
\hline
\end{tabular}

Kako kalorijska vrednost drveta zavisi od vlage i iskoristivosti ložišta, korisna kalorijska vrednost data u tabeli 2 ce biti niža. U tabeli 3 je data kalorijska vrednost drveta u zavisnosti od procenta vlage i iskoristivosti ložišta [7]. 
Tabela 3. Kalorijska vrednost drveta u zavisnosti od vlage i stepena iskorišćenja ložišta

\begin{tabular}{|c|c|c|c|}
\hline $\begin{array}{c}\text { Vlaga } \\
(\%)\end{array}$ & $\begin{array}{c}\text { Donja } \\
\text { toplotna } \\
\text { moć } \\
\mathrm{KJ} / \mathrm{kg}\end{array}$ & $\begin{array}{c}\text { Stepen } \\
\text { iskorišćenja } \\
\text { ložišta }(\%)\end{array}$ & $\begin{array}{c}\text { Korisna } \\
\text { toplota } \\
\mathrm{KJ} / \mathrm{kg}\end{array}$ \\
\hline 0 & 19,8 & 80 & 15,8 \\
\hline 10 & 17,8 & 78 & 13,9 \\
\hline 40 & 14,5 & 74 & 12,1 \\
\hline 70 & 12,0 & 72 & 8,6 \\
\hline
\end{tabular}

Kalorijska vrednost otpadnog drvnog materijala iz proizvodnje šperploče, uzimajući u obzir da je prosečna kalorijska toplota $12,6 \mathrm{MJ} / \mathrm{kg}$ mogla bi da se kreće oko 711000 GJ. Moguća ostvarena korisna toplota u KWh se može dobiti ukoliko se preračuna da je $1 \mathrm{MJ}=0,278 \mathrm{KWh}$. Dobija se da $\mathrm{u}$ toku godine potencijalna korisna energija iz otpadnog drvnog materijala iz proizvodnje šperploče iznosi 197658 KWh ili dnevno 541,5 KWh/dan.

\section{Zaključak}

Analizom podataka o otpadnom drvnom materijalu iz proizvodnje šperploča $u$ fabrici Wizard-Vršac, primenom statističke metode došlo se do podatka da se korišćenjem otpadnog materijala iz različitih faza prerade drveta, polazeći od sirovog trupca topole do završnog proizvoda šperploče, može dobiti korisna energija od $197658 \mathrm{KWh}$ za godinu dana ili 541,5 $\mathrm{KWh} /$ dan. Ovo predstavlja značajnu uštedu, kao i održivo korišćenje otpadnih materijala, posebno jer se radi o obnovljivom izvoru energije.

\section{Bibliografija}

1. Report: Forest and Forest products Country Profile - Serbia and Montenegro, Discussion Paper 40, UN Economic Commission for Europe, 2005.

2. Waste, Environmental statistics and accounts in Europe, 2010.

3. Biomass Statistics: Wood waste, Update: 5th edition, Prepared for the Danish Energy Agency by FORCE Technology, October 2011.
4. Bukurov, M. Z., et.al.: Finding the Balance between the Energy Security and S24 Thermal Science:, Vol. 14, Suppl., pp. S15-S25, 2010.

5. Nikolaos R., Carola D., Eurostat, Statistics in focus, Environment and energy, , Patriyia Noizette, 56/2010.

6. Report: Country Market Statement of Serbia, published by UNECE Timber Committee, Geneva, 2006.

7. Danob G. Energetika u drvnoj industriji, Šumarski fakultet Beograd, Beograd, 2001.

\section{Istorija rada:}

Rad primljen: 25.04.2013.

Prva revizija: 21.05.2013.

Druga revizija: 30.05.2013.

Prihvaćen: 01.06.2013. 